\title{
Senary Refractory High-Entropy Alloy $\mathrm{Cr}_{x} \mathrm{MoNbTaVW}$
}

\author{
B. Zhang ${ }^{1}$, M.C. Gao ${ }^{2,3}$, Y. Zhang ${ }^{1}$, S.M. Guo ${ }^{1 \mathrm{a}}$ \\ ${ }^{1}$ Louisiana State University, Baton Rouge, LA 70803, USA \\ ${ }^{2}$ National Energy Technology Laboratory, Albany, OR 97321, USA \\ ${ }^{3}$ AECOM, P.O. Box 1959, Albany, OR 97321, USA
}

\begin{abstract}
This paper demonstrates that a senary refractory high-entropy alloy $\mathrm{Cr}_{\mathrm{x}} \mathrm{MoNbTaVW}$ can be tailored over a certain range of $\mathrm{Cr}$ content with the BCC structure for different microstructures and physical properties, assisted by CALPHAD simulations. Microstructure characterizations are performed using X-ray diffraction and scanning electron microscopy. Chemical microsegregation during solidification predicted using the Scheil model generally agrees with the experimental results. The lattice constant, density, and Vickers' micro-hardness of the highentropy alloy samples in the as-cast state are measured and discussed. For $\mathrm{Cr}_{\mathrm{x}} \mathrm{MoNbTaVW}$, $\mathrm{x}=2.0$ case appears exceeding the upper limit of maintaining a single BCC phase HEA, determined by the XRD patterns. The elemental dependence of the mixing thermodynamic properties (entropy, enthalpy and Gibbs energy) in BCC phase in the senary system is analyzed. The calculated entropy of mixing and enthalpy of mixing for CrMoNbTaVW are $14.7 \mathrm{~J} / \mathrm{K} / \mathrm{mol}$ and $-662.5 \mathrm{~J} / \mathrm{mol}$ respectively.
\end{abstract}

\section{Keywords}

Alloy design; High entropy alloy; CALPHAD; Microstructure; Phase diagram;

\section{Introduction}

Refractory alloys are used in many industry sectors - chemical processing, aerospace, and microelectronics. To design a refractory alloy, the conventional design approach is to use single principal metal refractory elements, such as $\mathrm{W}, \mathrm{Mo}, \mathrm{Nb}$, and Ta. Using single-element based alloy design imposes limitations, not only in terms of compositional availabilities, but also the range of achievable properties. Poor low-temperature ductility and low oxidation resistance are common shortfalls for conventional refractory alloys[1].

A new alloy development strategy, namely multi-principal-element alloys or high-entropy alloys (HEAs), has been proposed by Yeh et al. [2] and developed by many researchers in recent years. The HEA approach employs five or more principal metallic elements at near equal molar ratios in a solid solution, with atomic percentage of each element varying between 5\% and 35\%. The high configurational entropy of mixing can stabilize solid-solution phases than intermetallic phases. As reported in literature, HEAs can be tailored to possess excellent wear and oxidation resistance [3], high temperature strength [4] and low temperature ductility [5]. Recently, a new branch of refractory alloys - refractory HEAs - has been proposed and characterized by Senkov

\footnotetext{
${ }^{a}$ Dept. Mechanical and Industrial Engineering, Louisiana State University, Baton Rouge, LA 70803, USA sguo2@1su.edu, 12255787619
} 
et al. [6-8] by extending the HEA design concept to refractory alloys. It has been shown that the high temperature strength of refractory HEAs MoNbTaW and MoNbTaVW with the bodycentered cubic (BCC) structure at high temperatures are even higher than that of conventional super-alloys [6]. Other HEA compositions, such as MoNbTaTiVW [9], HfMoTaTiZr [8], HfNbTaTiVZr [10] and HfMoNbTaTiZr [11], were also experimentally studied. However, to date the progresses in the design and validation of refractory HEAs are slow, mainly due to the lack of effective design guidance. For a typical HEA composition of more than five principal elements, the combinatorial possibilities follow factorial growth. Recently an efficient strategy was proposed by Gao and Alman $[12,13]$ to accelerate single-phase HEA design by integrating experimental phase diagram inspection, CALPHAD (CALculation of PHAse Diagrams) modeling and first-principle density functional theoretical calculations.

The goal of this paper is to demonstrate that senary refractory high-entropy alloys $\mathrm{Cr}_{\mathrm{x}} \mathrm{MoNbTaVW}(\mathrm{x}=0.5,1$, and 2 in molar ratio) can be tailored over a certain range of $\mathrm{Cr}$ contents to form BCC phase HEAs with different microstructures and physical properties. The phase stability of $\mathrm{Cr}_{\mathrm{x}} \mathrm{MoNbTaVW}$ HEAs was first evaluated using the CALPHAD method. Then experimental effort was applied to validate the phase structures, the microstructures, and the influence of $\mathrm{Cr}$ content. Formation of single BCC phase MoNbTaVW HEA has been reported by Senkov et al. [6] who identified all peaks on the X-ray diffraction (XRD) patterns of MoNbTaVW in the as-cast condition to be a single BCC phase, despite the presence of elemental segregation associated with the dendritic microstructure. However, proper homogenization and subsequent annealing (or thermo-mechanical processing) are required to achieve chemical homogeneity and thus to further improve mechanical and other properties.

\section{CALPHAD modeling}

\subsection{Phase diagrams}

All the CALPHAD modeling were carried out using the TCNI7 thermodynamic database via ThermoCalc $^{\mathrm{TM}}$ software [14]. Although TCNI7 database is primarily optimized for Ni-based super-alloys, it does cover all the edge binaries of the Cr-Mo-Nb-Ta-V-W system. To show the influence of $\mathrm{Cr}$ addition to the MoNbTaVW system, the pseudo-binary phase diagram of $\mathrm{Cr}_{\mathrm{x}}$ MoNbTaVW is shown in Fig. 1. For $\mathrm{x} \leqslant 5$, the BCC phase is the primary crystallization phase. With increasing $\mathrm{Cr}$ molar ratio, both the liquidus and solidus temperatures decrease while the solvus temperature increases. As a result, the single BCC phase field shrinks with the increasing of $\mathrm{Cr}$ ratio, due to the formation of competing $\mathrm{BCC \# 2}$ phase that is rich in $\mathrm{Cr}$ and $\mathrm{V}, \mu$ phase, and $\mathrm{C} 15$ phase. Predicted equilibrium compositions of BCC\#1 and BCC\#2 are listed in Table 1. The pseudo-binary phase diagram with a wider $\mathrm{Cr}$ content can be found in supplementary [14]. 


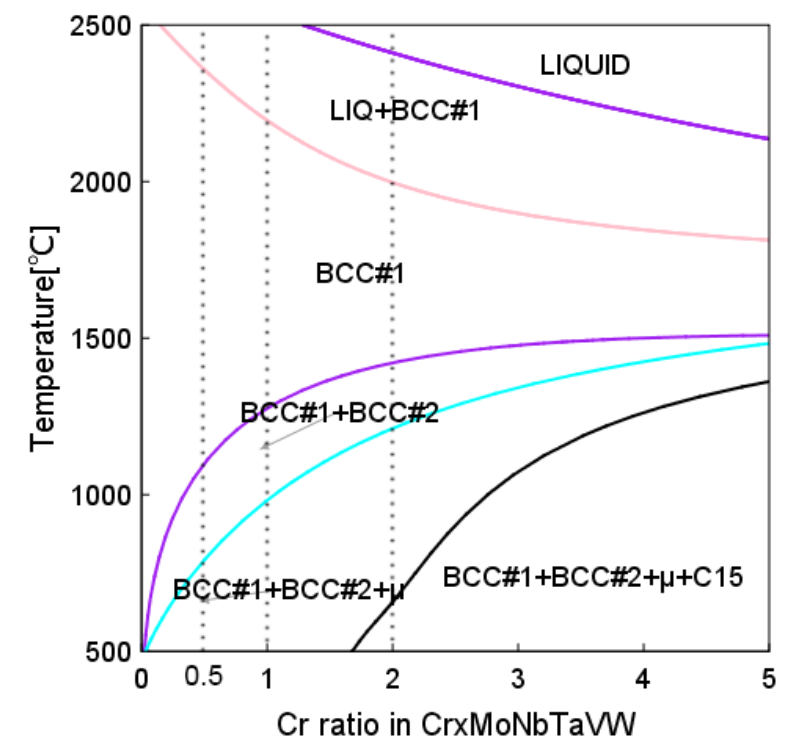

Fig. 1. Predicted pseudo-binary section of $\mathrm{Cr}_{\mathrm{x}} \mathrm{MoNbTaVW}$

Table 1. Predidcted equilibrum phase compositions at (at.\%).

\begin{tabular}{llllllll}
\hline Condition & Phase & $\mathrm{Cr}$ & $\mathrm{Mo}$ & $\mathrm{Nb}$ & $\mathrm{Ta}$ & $\mathrm{V}$ & $\mathrm{W}$ \\
\hline $\mathrm{x}=0.5$ & BCC\#1 & 6.1 & 19.2 & 19.2 & 19.3 & 17.0 & 19.2 \\
$\mathrm{~T}=1000{ }^{\circ} \mathrm{C}$ & $\mathrm{BCC \# 2}$ & 54.8 & 3.0 & 1.9 & 1.0 & 36.0 & 3.3 \\
$\mathrm{x}=1$ & $\mathrm{BCC \# 1}$ & 5.7 & 20.2 & 20.4 & 20.6 & 13.0 & 20.1 \\
$\mathrm{~T}=1000{ }^{\circ} \mathrm{C}$ & $\mathrm{BCC \# 2}$ & 61.0 & 2.6 & 1.5 & 0.8 & 31.4 & 2.7 \\
$\mathrm{x}=2$ & BCC\#1 & 16.8 & 17.6 & 17.9 & 18.5 & 11.4 & 17.8 \\
$\mathrm{~T}=1300{ }^{\circ} \mathrm{C}$ & $\mathrm{BCC \# 2}$ & 60.6 & 5.4 & 4.4 & 2.9 & 22.0 & 4.7 \\
\hline
\end{tabular}

\subsection{Solidification of Cr-Mo-Nb-Ta-V-W}

Predicted equilibrium and non-equilibrium solidification (Figure 2b-2d, 2f, 2h) behaviors of $\mathrm{Cr}_{\mathrm{x}} \mathrm{MoNbTaVW}$ are shown in Figure 2. The predicted equilibrium phase mole fraction plots (Figure 2a, 2e, 2g) show formation of a single BCC phase at higher temperatures. The BCC phase starts to form at $2540{ }^{\circ} \mathrm{C}$ in $\mathrm{CrMoNbTaVW}, 2616{ }^{\circ} \mathrm{C}$ for $\mathrm{x}=0.5$, and $2683{ }^{\circ} \mathrm{C}$ for $\mathrm{x}=2$. The BCC\#2 phase starts to form at $\mathrm{T} \leq 1276{ }^{\circ} \mathrm{C}$ for $\mathrm{CrMoNbTaVW}, \mathrm{T} \leq 1100{ }^{\circ} \mathrm{C}$ for $\mathrm{x}=0.5$, and at $\mathrm{T} \leq 1421{ }^{\circ} \mathrm{C}$ for $\mathrm{x}=2$.

The actual cooling rate of the HEA sample preparation process, in a lab arc melting furnace, is way higher than the equilibrium assumption, thus it is expected that the observed microstructures may deviate from the predicted equilibrium solidification. The non-equilibrium solidification was simulated using the Scheil-Gulliver models [15, 16], which assumed equilibrium in the liquid but no diffusions in the solid phase(s). Only disordered BCC phase (BCC\#1) was observed at $\mathrm{T} \geqslant 1607^{\circ} \mathrm{C}$ for $\mathrm{CrMoNbTaVW}$ (Fig. 2(b)), $\mathrm{T} \geqslant 1705^{\circ} \mathrm{C}$ for $\mathrm{x}=0.5$ (Fig. 2(e)), and $\mathrm{T} \geqslant 1604{ }^{\circ} \mathrm{C}$ for $\mathrm{x}=2$ (Fig. 2(g)). The BCC phase is found to be the disordered 
type [14]. The elemental composition evolutions in the liquid and BCC phases during the Scheil solidification are shown in Fig. 2(c) and (d) respectively to evaluate the possible microsegregation in CrMoNbTaVW. At the beginning of solidification, it is predicted that $\mathrm{W}, \mathrm{Ta}$ and Mo are depleted in the liquid while $\mathrm{Cr}$ and $\mathrm{V}$ are enriched. The solid BCC phase in the form of dendrites observed in the experiments is predicted to be enriched in $\mathrm{W}$, Ta and Mo but depleted in $\mathrm{Cr}$ and $\mathrm{V}$. At the later stages of the solidification where the inter-dendrites form, it predicts that inter-dendrites will be enriched in $\mathrm{Cr}$ and $\mathrm{V}$ but depleted in $\mathrm{W}$ and Ta. The Scheil-Gulliver solidification for $\mathrm{Cr}_{2} \mathrm{MoNbTaVW}$ predicates the formation of $\mathrm{C} 14$ laves phase and $\mathrm{C} 15$ laves phase at the last stage of the solidification. However, the predicted contents of $\mathrm{C} 14$ and $\mathrm{C} 15$ phases are extremely low $(0.23 \%$ and $0.81 \%)$, and they were not detected by the XRD measurements. In short, the non-equilibrium solidification simulations suggest that microsegregation is very likely to occur in alloy CrMoNbTaVW.
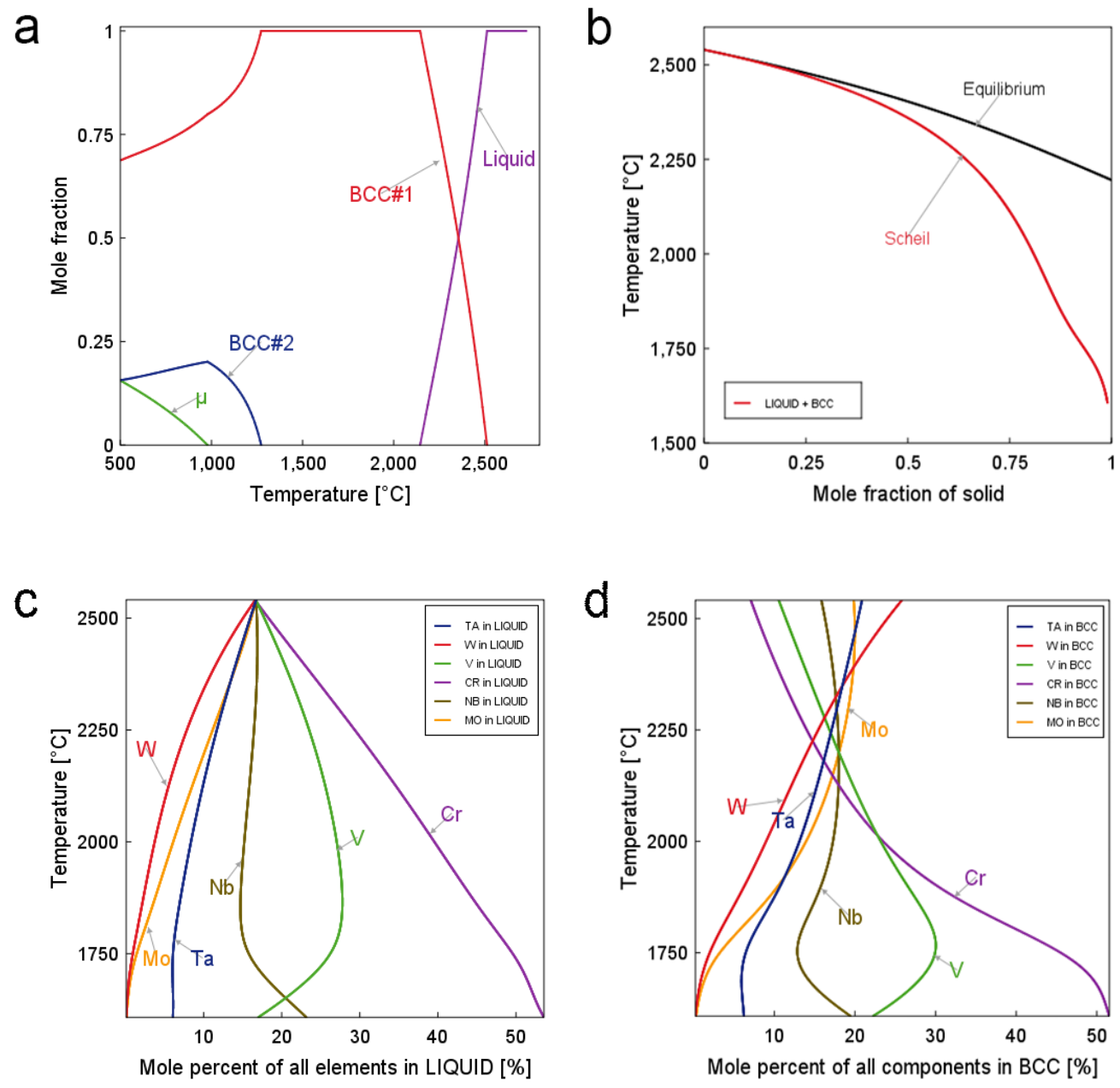

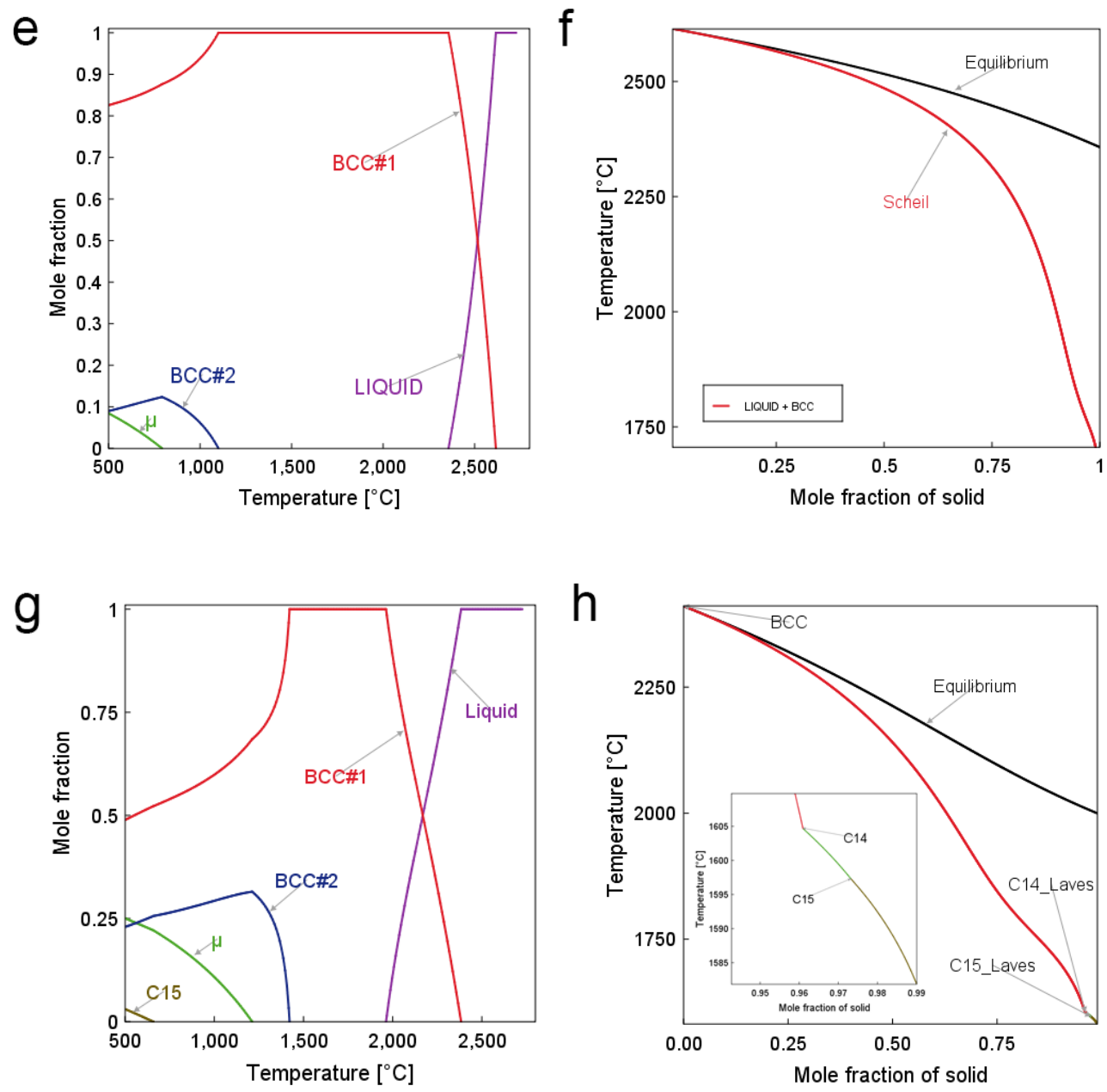

Fig. 2. Predicted equilibrium phase mole fraction: (a) $\mathrm{Cr}_{1} \mathrm{MoNbTaVW}$, (e) $\mathrm{Cr}_{0.5} \mathrm{MoNbTaVW}$ and (g) $\mathrm{Cr}_{2.0} \mathrm{MoNbTaVW}$; Scheil solidification: sold phase mole fraction (b) $\mathrm{Cr}_{1} \mathrm{MoNbTaVW}$, (f) $\mathrm{Cr}_{0.5} \mathrm{MoNbTaVW}$ (h) $\mathrm{Cr}_{2.0} \mathrm{MoNbTaVW}$; the composition of (c) the liquid phase and (d) BCC phase in $\mathrm{Cr}_{1} \mathrm{MoNbTaVW}$.

\section{Experimental results and discussions}

\subsection{Material synthesis and characterization methods}

The refractory HEA $\mathrm{Cr}_{\mathrm{x}} \mathrm{MoNbTaVW}$ system with different chromium contents $(\mathrm{x}=0.5,1$, and 2) was prepared by arc melting (model Edmund Bühler /MAM-1) the constituent elements in a water-cooled copper hearth to validate the CALPHAD modeling. Around 2 gram of commercial chromium, molybdenum, niobium, tantalum, vanadium and tungsten powders in total, with purity higher than $99.5 \%$, were mixed inside a polystyrene ball mill jar before melting. During the melting process, the ingots were inverted and re-melted for 4 times to ensure homogeneity. The cooled ingots were then mounted into epoxy resin (SamplKwick fast cure acrylic resin, produced by Buehler) for easy handing and retention. The mounted specimens 
were cut through the ingot using a low-speed saw in order to expose a flat surface of the sample cross-section. The exposed surface was subsequently ground by \# 240, \#400, \#600, and \#800 $\mathrm{SiC}$ sandpapers in sequence, before wet-polished with $1,0.3$ and $0.05 \mu \mathrm{m} \mathrm{Al}_{2} \mathrm{O}_{3}$ suspensions. An X-ray diffractometer (Empyrean, PANalytical) equipped with $\mathrm{Cu} \mathrm{K} \alpha$ radiation $(\lambda=0.15406$ $\mathrm{nm}$ ) was used for the identification of the structure, with the $2 \theta$ scan ranging from 5 to 145 degrees at a rate of 10 degree per min at $45 \mathrm{kV}$ and $40 \mathrm{~mA}$. Field-emission scanning electron microscope FE-SEM (FEI, Quanta 3DFEG) equipped with backscatter electron (BSE) and energy dispersive spectroscopy (EDS) detectors was used to characterize the microstructure and the chemical compositions of the samples along the cross-sections.

The bulk compositions of the alloys were estimated by EDS area scan, as listed in Table 2. The different evaporation losses during the arc-melting process caused a small deviation from the design point. The elemental proportions of Table 2 are used as the bulk concentrations to estimate the theoretical average properties of density, hardness and lattice constant. The measured compositions were also used to rerun the CALPHAD simulations for $\mathrm{Cr}_{\mathrm{x}} \mathrm{MoNbTaVW}$ $(\mathrm{x} \approx 0.5,1,2)$ and the results/features were found to be very similar to the results presented in Fig. 2 [14].

Table 2. EDS bulk composition analysis results for $\mathrm{Cr}_{\mathrm{x}} \mathrm{MoNbTaVW} \mathrm{HEA}$, (at.\%).

\begin{tabular}{ccccccc}
\hline & $\mathrm{Cr}$ & $\mathrm{Mo}$ & $\mathrm{Nb}$ & $\mathrm{Ta}$ & $\mathrm{V}$ & $\mathrm{W}$ \\
\hline $\mathrm{x} \approx 0.5$ & 8.43 & 16.95 & 19.65 & 15.91 & 23.10 & 15.95 \\
$\mathrm{x} \approx 1.0$ & 17.89 & 16.31 & 18.15 & 13.94 & 19.59 & 14.12 \\
$\mathrm{x} \approx 2.0$ & 27.05 & 13.68 & 13.63 & 13.64 & 15.18 & 16.81 \\
\hline
\end{tabular}

The density of the specimen was determined by measuring the samples' weight and volume. An analytical digital balance (Scientech, SA210) with a precision of $0.1 \mathrm{mg}$ was used to measure the weight. Archimedes' principle was used to determine the sample volume. The hardness of the specimen was measured using a Vickers micro hardness tester under a load of $1 \mathrm{kgf}$ for 15 seconds.

\subsection{X-ray diffraction of $\mathrm{Cr}_{\mathrm{x}} \mathrm{MoNbTaVW}$}

XRD patterns of the premixed metal powders and the as-solidified $\mathrm{Cr}_{\mathrm{X}} \mathrm{MoNbTaVW} \mathrm{HEA}$ samples are shown in Fig. 3. The XRD peaks of $\mathrm{Cr}, \mathrm{Mo}, \mathrm{Nb}, \mathrm{Ta}, \mathrm{V}$ and $\mathrm{W}$ can be traced in the ball-mixed powders. However, after the arc-melting process, all the crystalline structures of the alloys are confirmed to be $\mathrm{BCC}$ phases, with a minor difference of the lattice constants. With increasing the $\mathrm{Cr}$ content from $\mathrm{x}=0.5,1$, to 2, lattice constant of the $\mathrm{BCC}$ phase decreases from $0.31899 \pm 0.00013 \mathrm{~nm}, 0.31826 \pm 0.00049 \mathrm{~nm}$ to $0.31583 \pm 0.00035 \mathrm{~nm}$ respectively. Despite the presence of elemental micro-segregation in these samples presented in section 3.3, these values agree well with the ones estimated from the mixture rule, as shown in Table 3 . As expected, the increase of $\mathrm{Cr}$ content leads to the decrease of the lattice constant, which agrees with the experimental results.

Table 3. The experimental lattice constant $a$, Vickers hardness $H V$, density $\rho$ of the HEA alloy and the estimated average (experimental/ estimated [17]). 


\begin{tabular}{cccc}
\hline & Vickers hardness, $H V$ & $\rho^{*}, \mathrm{~g} / \mathrm{cm}^{3}$ & $a, \mathrm{~nm}$ \\
\hline TiMoNbTaVW[9] & $505.1(4954 \mathrm{MPa})$ & $11.7 / 11.19$ & $0.3216 / 0.3174$ \\
MoNbTaVW [6] & $535.3 \pm 28.6(5250 \mathrm{MPa})$ & $12.36 / 12.36$ & $0.31832 / 0.31827$ \\
$\mathrm{Cr}_{0.5} \mathrm{MoNbTaVW}$ & $675.5 \pm 27.5(6624.7 \pm 269.2 \mathrm{MPa})$ & $11.5 / 11.4$ & $0.31899 / 0.31586$ \\
$\mathrm{Cr}_{1.0} \mathrm{MoNbTaVW}$ & $704.6 \pm 17.4(6910.3 \pm 170.5 \mathrm{MPa})$ & $11.4 / 11.1$ & $0.31826 / 0.31290$ \\
$\mathrm{Cr}_{2.0} \mathrm{MoNbTaVW}$ & $754.9 \pm 43.1(7403.4 \pm 422.5 \mathrm{MPa})$ & $11.2 / 11.4$ & $0.31583 / 0.31103$ \\
\hline
\end{tabular}

* Estimated data were calculated using equation (1).

In the XRD pattern of $\mathrm{x}=2.0$, apparent secondary $\mathrm{BCC}$ peaks appear beside the main $\mathrm{BCC}$ peaks with a smaller lattice constant. This observation is supported by phase diagram calculations, Figs. 1 and $2 \mathrm{~g}$. With $\mathrm{x}$ increasing from 0.5 to 2, the formation temperature for the secondary BCC increases. Thus it's more likely for the secondary BCC structure to form during the arc melting process.
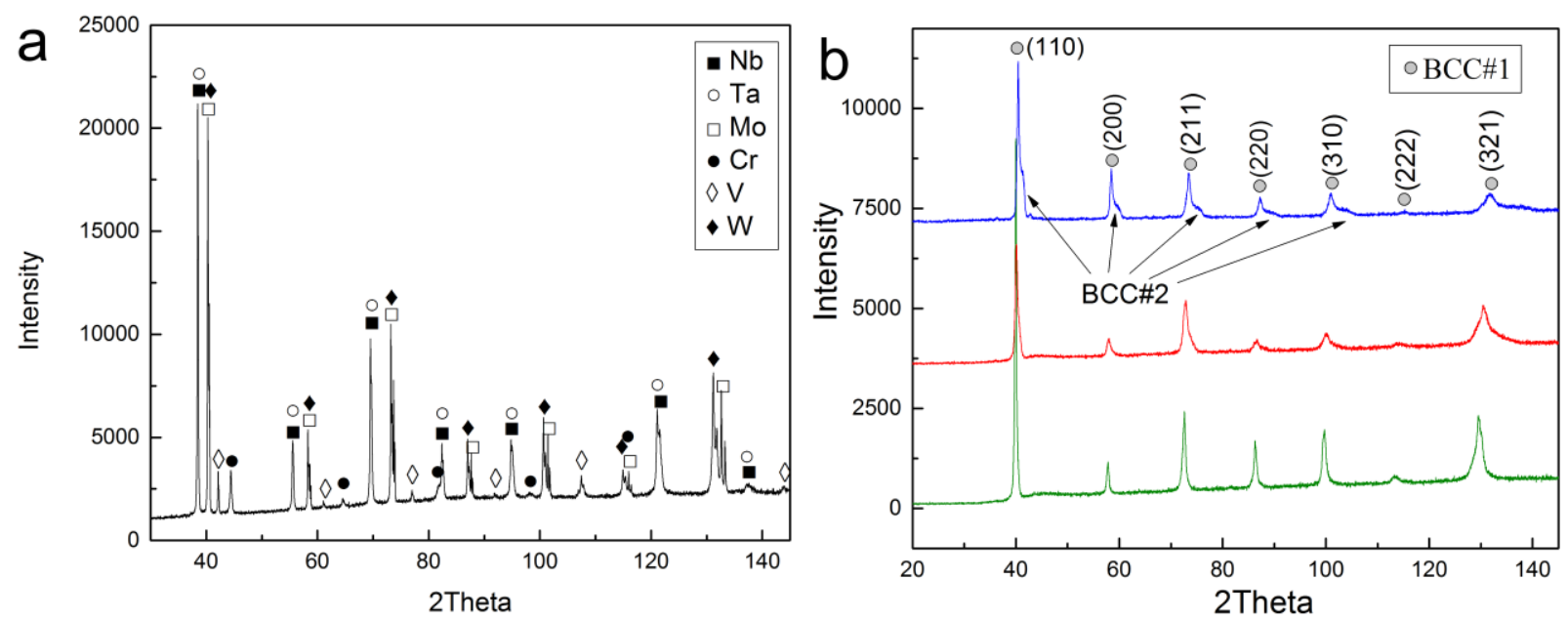

Fig. 3. XRD patterns of (a) mixed metal powders and (b) as-solidified $\mathrm{Cr}_{\mathrm{X}}$ MoNbTaVW alloys

\subsection{Microstructures for $\mathrm{Cr}_{\mathrm{x}} \mathrm{MoNbTaVW}$}

SEM backscatter electron images were taken separately on the finely polished surfaces of $\mathrm{Cr}_{\mathrm{x}} \mathrm{MoNbTaVW}(\mathrm{x}=0.5,1,2)$ HEA alloys. Typical solidification microstructures were observed in all samples. Fig. 4 shows the transition from a cellular structure to a dendritic structure as the $\mathrm{Cr}$ content increases. It is well known that the constitutional undercooling leads to the formation of dendritic structures [18]. The increase of the $\mathrm{Cr}$ concentration will lead to the increase of the undercooling effects. So as shown in Fig. 4 (a), when $x=0.5$, the undercooling is relatively weak, thus the cellular structure forms. With the $\mathrm{x}$ increases to 1.0, Fig. 4 (b), the stronger undercooling facilitates the growth of the primary dendrite arms to around $10 \mu \mathrm{m}$. As $\mathrm{x}$ goes even larger in Fig. 4 (c), the dendrite arms grow to around $30 \mu \mathrm{m}$ long and the branch arms start to form. 

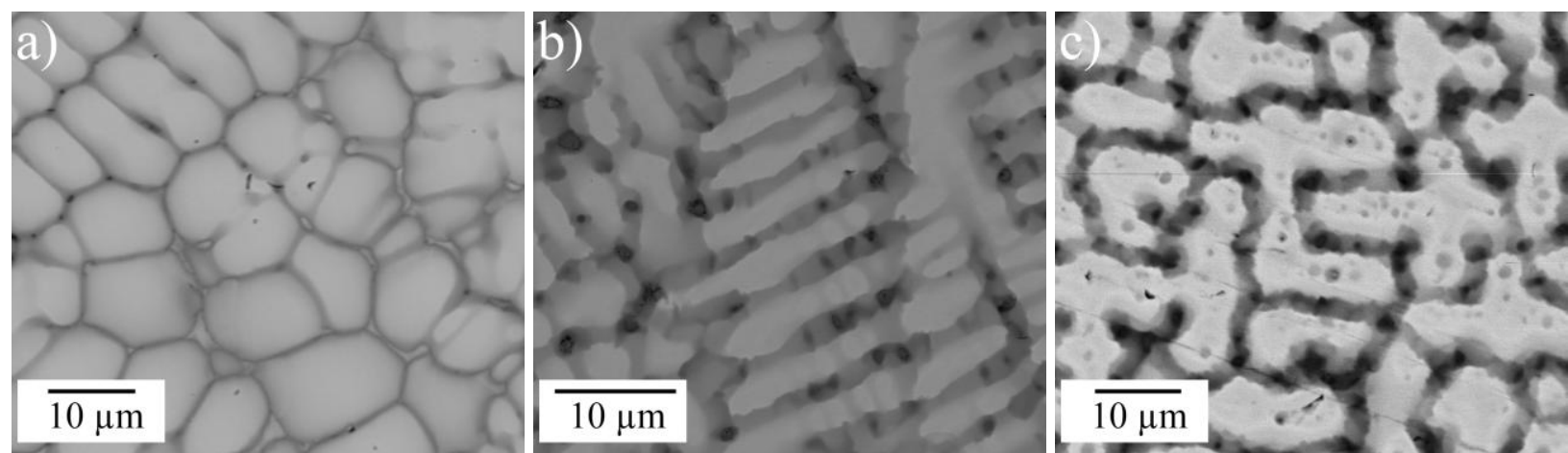

Fig. 4. SEM backscatter electron image of the HEA $\mathrm{Cr}_{\mathrm{x}} \mathrm{MoNbTaVW}$ : (a) $\mathrm{x}=0.5$, (b) $\mathrm{x}=1.0$, (c) $\mathrm{x}=2.0$

In dendritic growth, mass of low melting temperature solute is ejected between the dendrite arms and causes micro-segregation. In backscatter images (Fig.4), the heavier metal elements (higher atomic number $\mathrm{Z}$ ) have a brighter color. In this case, the order of brightness is $\mathrm{W}$ and $\mathrm{Ta}$ first, followed by Mo and $\mathrm{Nb}$, and $\mathrm{Cr}$ and $\mathrm{V}$ last. The micro-segregation was measured by EDS mapping, as shown in Figs. 5, 6 and 7. The Mo, Ta and $\mathrm{W}$ elements are clearly seen inside the dendritic structures, while most of other elements can be clearly seen with enrichments in the inter-dendritic regions.
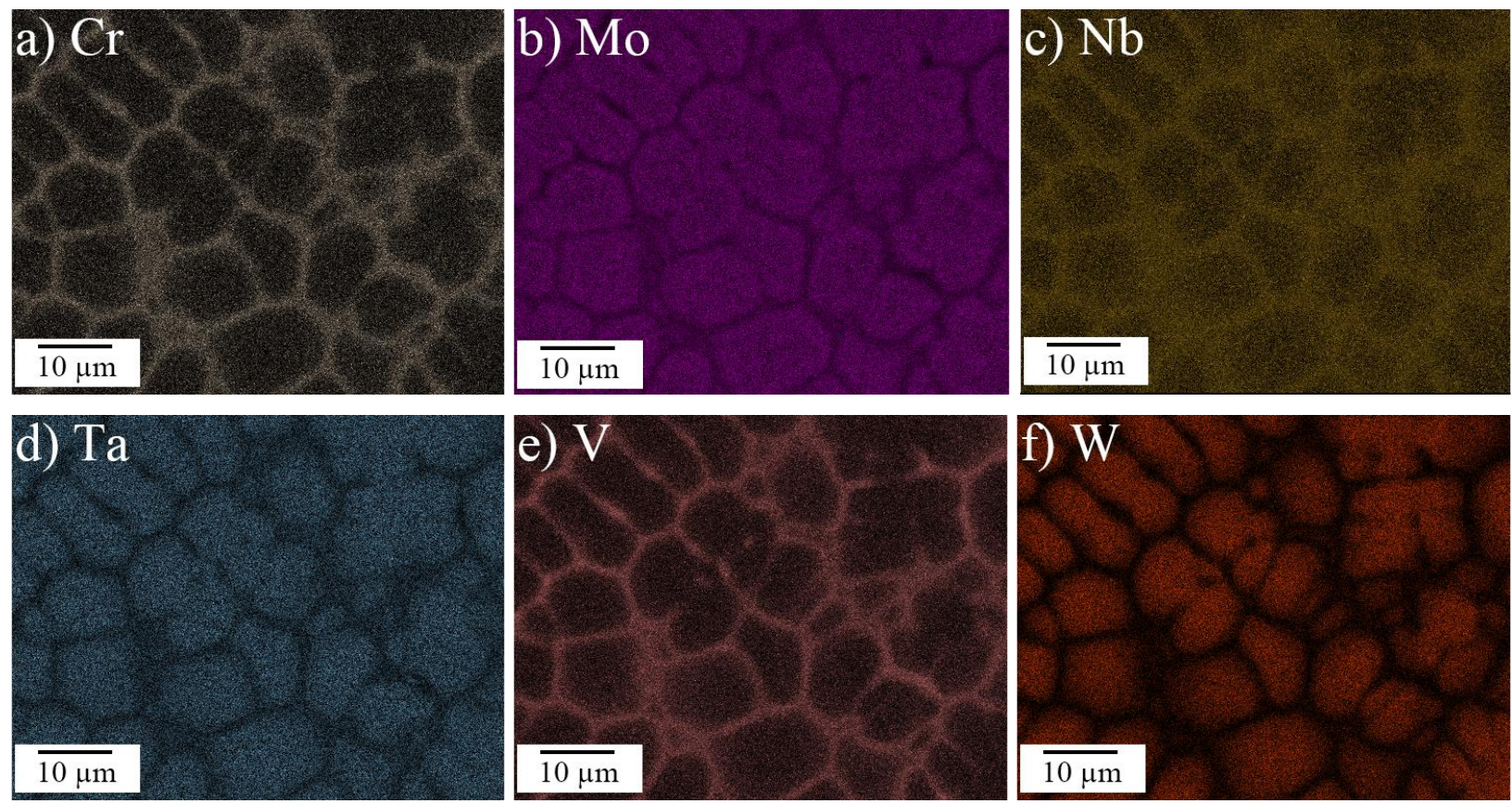

Fig. 5. EDS mapping of the HEA $\mathrm{Cr}_{0.5} \mathrm{MoNbTaVW}$ 

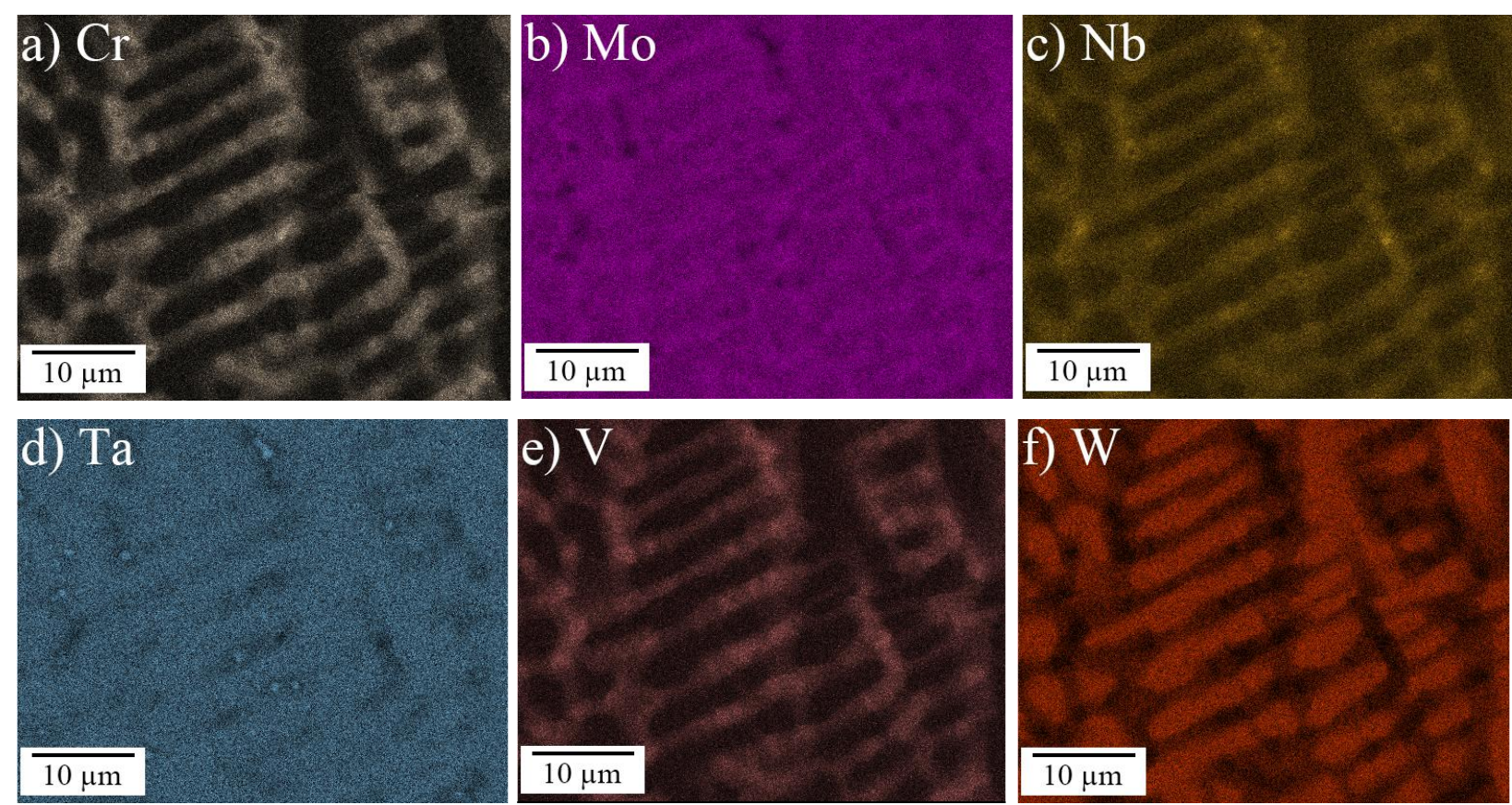

Fig. 6. EDS mapping of the HEA $\mathrm{Cr}_{1.0} \mathrm{MoNbTaVW}$
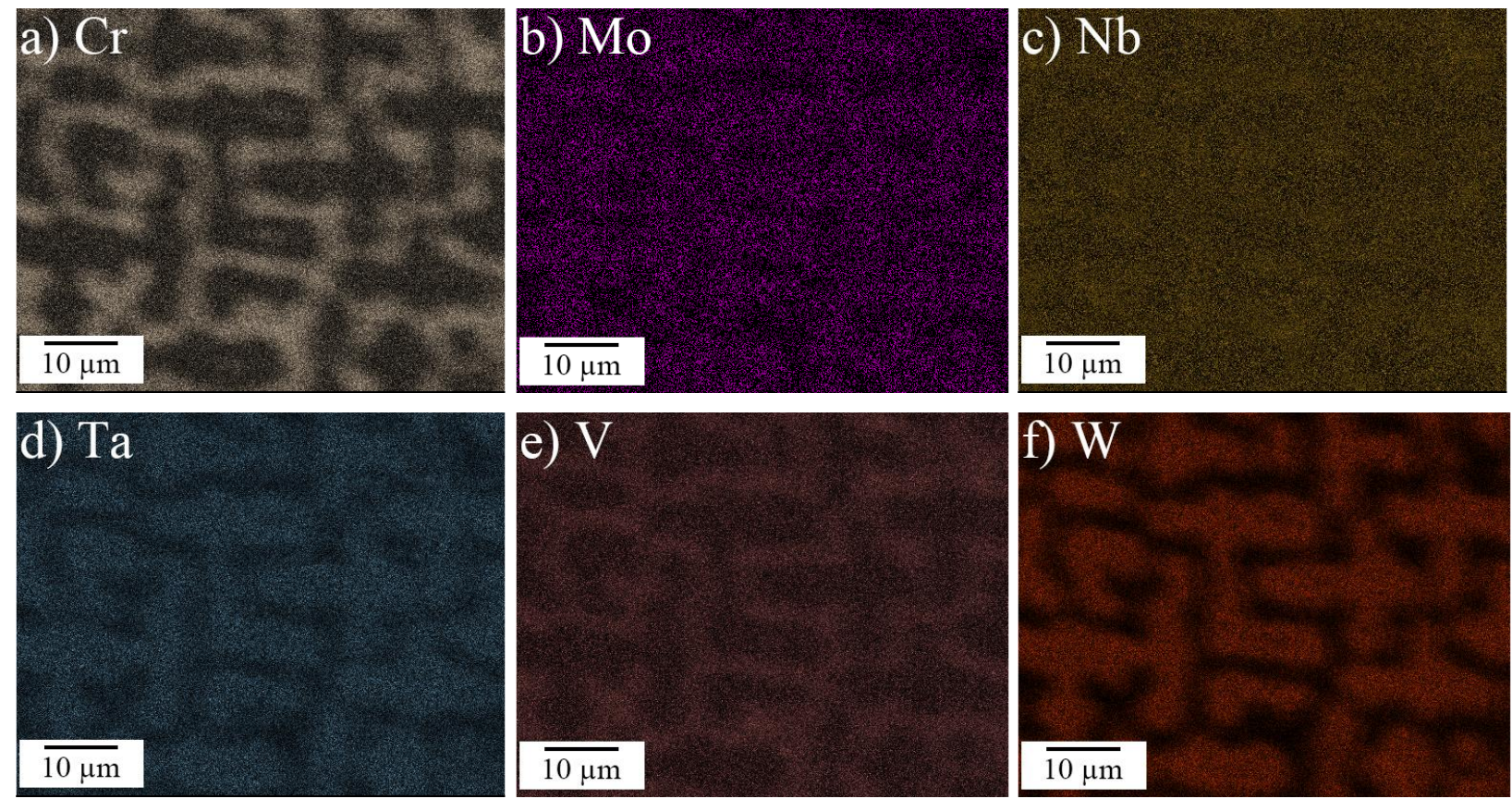

Fig. 7. EDS mapping of the HEA $\mathrm{Cr}_{2.0} \mathrm{MoNbTaVW}$ 
The micro-segregation between the dendrite and inter-dendrite regions can be quantitatively identified through the EDS point scans. The elemental percentages of each element were taken on both dendrite areas $\left(C_{d}\right)$ and inter-dendrite areas $\left(C_{i d}\right)$. Following Leo et al. [19], the partition cofficient $K=C_{d} / C_{i d}$, was used to evaluated the micro-segregation quantitatively. It can be shown that in dendrite region of all three samples, the enriched elements are $\mathrm{W}$ first, followed by $\mathrm{Mo}$, and then $\mathrm{Ta}$, while the inter-dendrite region was enriched in $\mathrm{Cr}$ followed by $\mathrm{V}$ and then $\mathrm{Nb}$. The sequence of the segregated elements qualitatively agrees with the prediction from Scheil model as shown in Fig. 2 ( $\mathrm{c}$ and $\mathrm{d})$. For $\mathrm{Cr}_{\mathrm{x}} \mathrm{MoNbTaVW}(\mathrm{x} \approx 0.5,1,2)$ partition coefficients, the lower end is $\mathrm{Cr}$ at $\mathrm{x} \approx 0.5$, with a value near $1: 9$, and the higher end is $\mathrm{W}$ at $\mathrm{x} \approx 2.0$, with a value close to 12:1, Table 4 .

Table 4. Partition cofficient $K$ of $\mathrm{Cr}_{\mathrm{x}} \mathrm{MoNbTaVW}$ HEA

\begin{tabular}{ccccccc}
\hline & $\mathrm{Cr}$ & $\mathrm{Mo}$ & $\mathrm{Nb}$ & $\mathrm{Ta}$ & $\mathrm{V}$ & $\mathrm{W}$ \\
\hline $\mathrm{x} \approx 0.5$ & $0.11(1: 9)$ & 1.60 & 0.50 & 1.14 & 0.17 & 5.50 \\
$\mathrm{x} \approx 1.0$ & 0.17 & 1.40 & 0.55 & 1.28 & 0.28 & 3.61 \\
$\mathrm{x} \approx 2.0$ & 0.34 & 4.18 & 0.83 & 1.46 & 0.55 & $11.66(12: 1)$ \\
\hline
\end{tabular}

The EDS line scan was used to quantify the level of element segregation between the dendrite arms and inter-dendritic regions. As shown in Fig. 8, the elemental compositions were collected at points along a straight line across the dendrites and inter-dendrites with an interval separation of $0.1 \mu \mathrm{m}$.
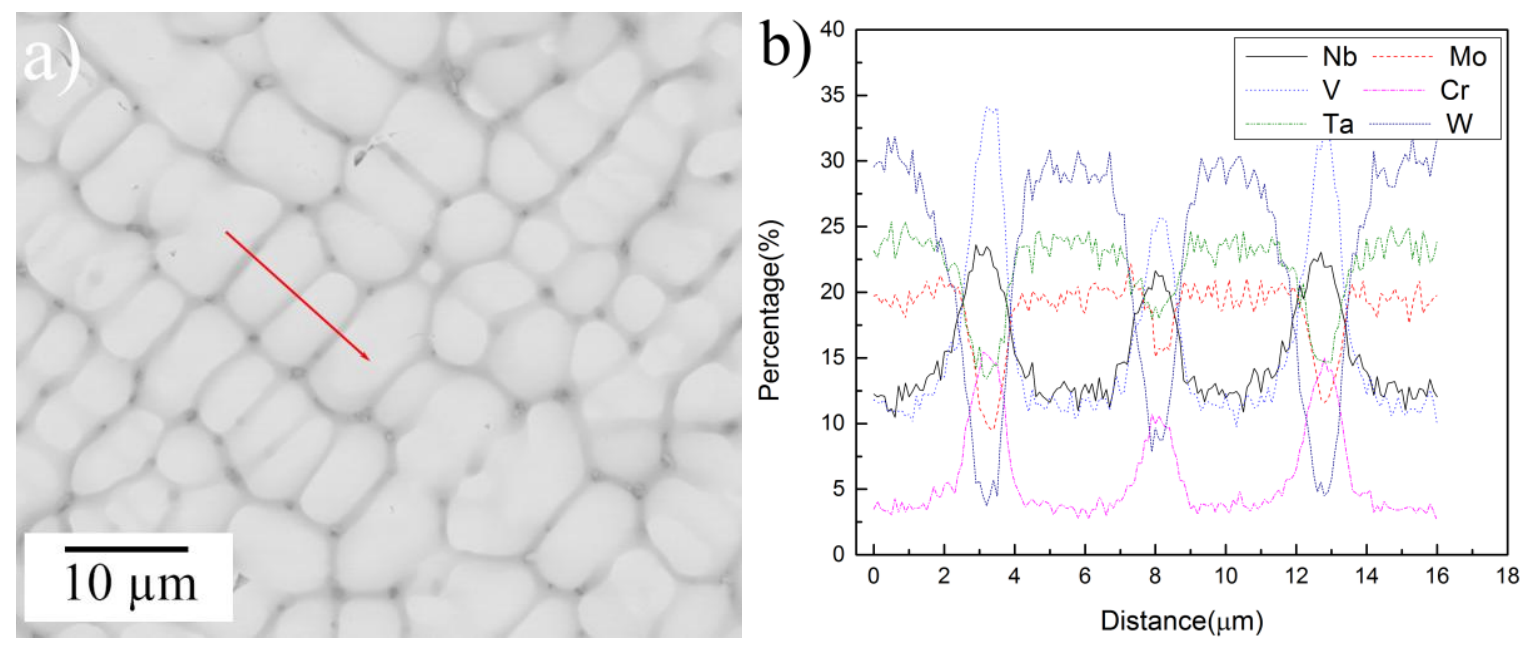

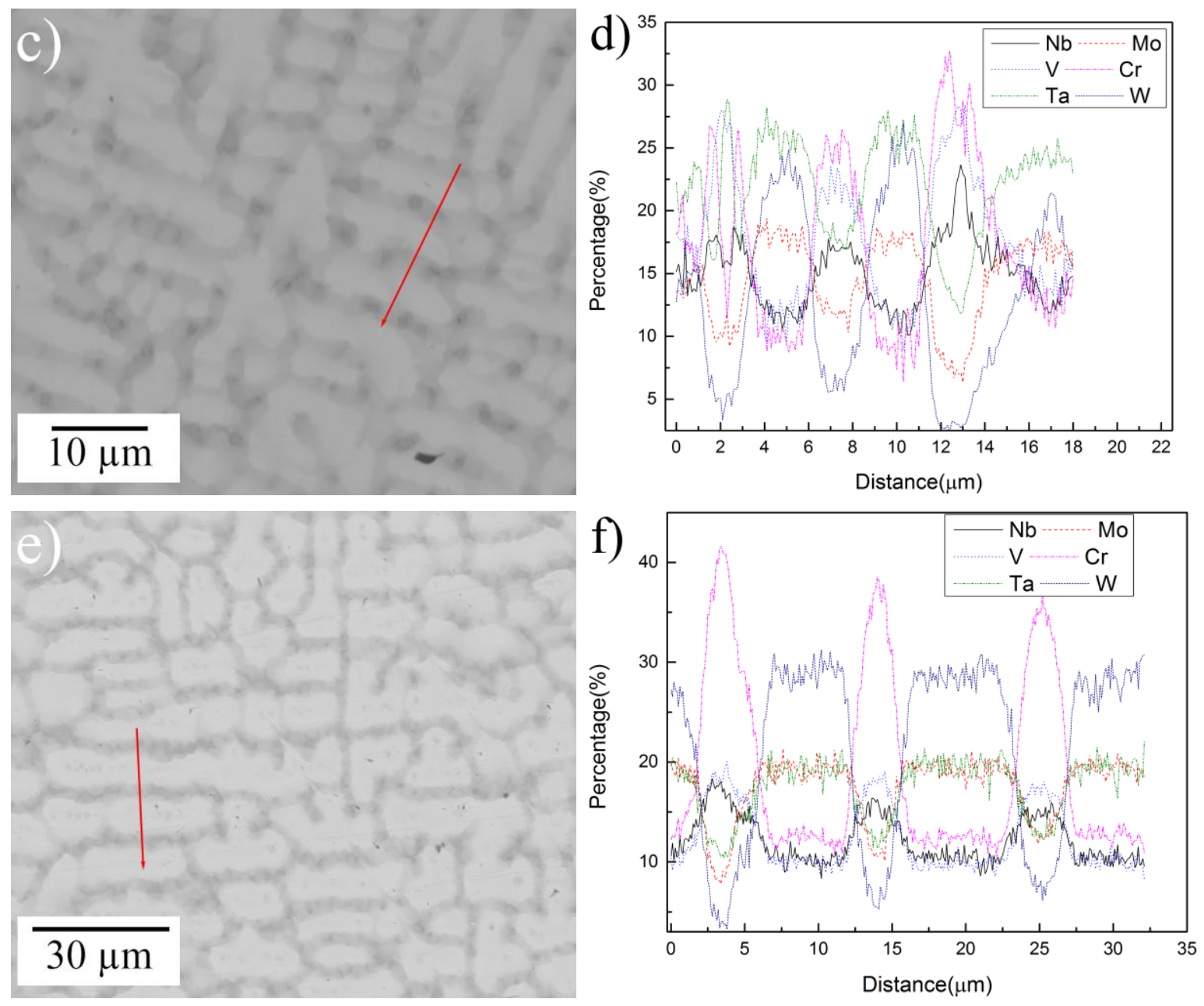

Fig. 8. SEM image with EDS line measurement locations marked of (a) $x=0.5$, (c) $x=1.0$, (e) $x=2.0$, and atom percentages of (b) $x=0.5$, (d) $x=1$, (f) $x=2$

\subsection{Density and hardness for $\mathrm{Cr}_{\mathbf{x}} \mathrm{MoNbTaVW}$}

The density, hardness, and lattice constant of quinary MoNbTaVW alloy, senary HEAs $\mathrm{Cr}_{\mathrm{x}} \mathrm{MoNbTaVW}$, and TiMoNbTaVW were listed in Table 3 to demonstrate the effect of introducing $\mathrm{Cr}$ or $\mathrm{Ti}$ into the base alloy MoNbTaVW. The densities of the $\mathrm{Cr}_{\mathrm{x}} \mathrm{MoNbTaVW}$ alloys were determined to be $11.5 \mathrm{~g} / \mathrm{cm}^{3}$ for $\mathrm{x}=0.5,11.4 \mathrm{~g} / \mathrm{cm}^{3}$ for $\mathrm{x}=1.0$, and $11.2 \mathrm{~g} / \mathrm{cm}^{3}$ for $\mathrm{x}=2.0$ (see Table 3). To compare with the experimental results, the density of a disordered solid solution can be estimated from the rule of mixture:

$$
\rho_{\text {est }}=\frac{\sum c_{i} A_{i}}{\sum \frac{c_{i} A_{i}}{\rho_{i}}}
$$

where $c_{i}$ is the atomic percentage of an element; $A_{i}$ is the atomic weight; and $\rho_{i}$ is the density of the pure element. The calculated theoretical densities are also listed in Table. 3. The measured densities of the HEAs are very close to the corresponding calculated ones. 
Table 5. The atomic radius $r$ of the metal feedstock [20].

\begin{tabular}{llllllll}
\hline Metal & $\mathrm{Ti}$ & $\mathrm{Cr}$ & $\mathrm{Mo}$ & $\mathrm{Nb}$ & $\mathrm{Ta}$ & $\mathrm{V}$ & $\mathrm{W}$ \\
\hline$r, \AA$ & 1.46 & 1.28 & 1.40 & 1.47 & 1.47 & 1.35 & 1.41 \\
\hline
\end{tabular}

The values of Vickers micro-hardness were measured across the polished surface of HEA samples. Five random sites were tested on each sample and the averaged values were summarized in Table 3. The hardness of $\mathrm{Cr}_{x} \mathrm{MoNbTaVW}$ were calculated to be $675.5 \pm 27.5$, $704.6 \pm 17.4$, and $754.9 \pm 43.1$ for $\mathrm{x}=0.5, \mathrm{x}=1.0$ and $\mathrm{x}=2.0$, respectively. The experimental micro-hardness values are dramatically higher than the hardest component $\mathrm{W}$ in the system. Since the $\mathrm{Cr}$ is the smallest element in the $\mathrm{Cr}_{\mathrm{x}} \mathrm{MoNbTaV}$ system, Table 5, adding more Cr into the system is expected to increase the atomic size misfit influence which will increase the hardness. Clearly, solid solution hardening mechanism plays an important role in this HEA system. Moreover, early study on the Ti addition into base alloy MoNbTaVW shows no hardening effect [9], since the radius of Ti is similar to rest of elements in the system. The small hardness difference between TiMoNbTaVW and MoNbTaVW is due to the grain size differences.

\section{Further discussions on CALPHAD thermodynamic analysis}

It is known that the Laves phases form in $\mathrm{Cr}-\mathrm{Nb}$ [21] , Cr-Ta [21], Nb-V [22], and Ta-V [21] binary systems, but the solubility of the Laves phases into the ternary systems of refractory metals is not huge [21]. Because both CALPHAD modeling (section 2) and experimental testing (section 3) state that disordered BCC solid solutions form in the CrMoNbTaVW alloys, more thermodynamic calculations were carried out on the BCC and $\mathrm{C} 15$ phases as a function of temperature and compositions. Fig. 9 compares the entropy, enthalpy and Gibbs energy of BCC and Laves phases in the senary CrMoNbTaVW alloy as a function of temperature using the default reference states (namely the stable structure at $25.15{ }^{\circ} \mathrm{C}$ and $1 \mathrm{~atm}$ ). The $\mathrm{BCC}$ phase has significantly larger entropy than the $\mathrm{C} 15$ phase while the enthalpy is lower for the $\mathrm{BCC}$ phase by a small amount. The temperature dependence of entropy is presumed due to the lattice phonon vibration that strongly depends upon temperature. For quantitative evaluation of entropy sources of high-entropy alloys, please refer to recent publications [21,22]. Note that direct comparison in the Gibbs energy between phases such as in Fig. 9c, 10c and 11c is most meaningful for single-phase region; for regions of co-existing phases, the tie-line is out of plane and thus the plots cannot be used for global phase equilibrium determination. Nonetheless, these plots show the trend of the Gibbs energy of each phase with respect to temperature and composition.
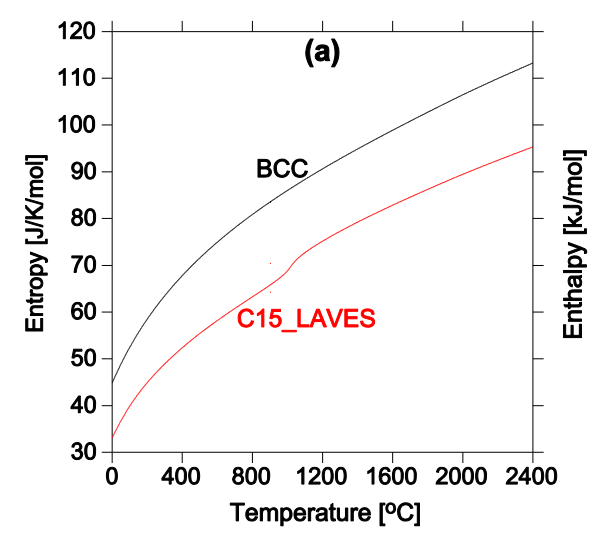
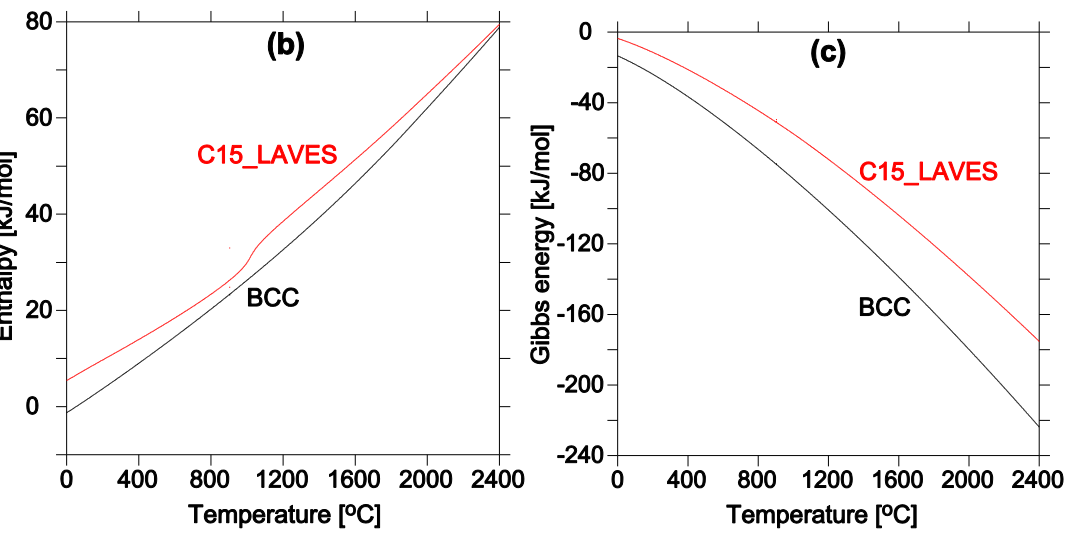
Fig. 9: calculated (a) entropy, (b) enthalpy and (c) Gibbs energy of the BCC and C15 Laves phases in CrMoNbTaVW as a function of temperature using the default reference states (namely the stable structure at $25.15^{\circ} \mathrm{C}$ and $1 \mathrm{~atm}$ )

The entropy of mixing $\left(\Delta S_{\text {mix }}^{b c c}\right)$ and enthalpy of mixing $\left(\Delta H_{\text {mix }}^{b c c}\right)$ for the BCC phase in CrMoNbTaVW can be calculated using the BCC phase as the reference. Below $2400{ }^{\circ} \mathrm{C}$, they are a constant of $14.7 \mathrm{~J} / \mathrm{K} / \mathrm{mol}$ and $-662.5 \mathrm{~J} / \mathrm{mol}$ respectively. That the short-range order is not considered in the BCC phase in the database is partly responsible for the constant values [21]. Future thermochemical measurements on entropy, enthalpy, and Gibbs energy for the senary CrMoNbTaVW alloy are desirable to compare with the predicted results.

Comparison in the thermodynamic mixing properties between the $\mathrm{BCC}$ and Laves phases in $\mathrm{Cr}_{\mathrm{x}} \mathrm{MoNbTaVW}$ at $1000{ }^{\circ} \mathrm{C}$ is shown in Fig. 10, which is obtained by excluding the mechanical mixing from the pure components. It is predicted that $\Delta S_{\text {mix }}^{b c c}$ reaches its maximum of +15.3 $\mathrm{J} / \mathrm{K} / \mathrm{mol}$ at 31.3 at. $\% \mathrm{Cr}$, which deviates substantially from the equi-molar composition. $\Delta S_{\text {mix }}^{C 15}$ evolves from negative to positive values with increasing $\mathrm{Cr}$ contents but the absolute value is very small compared to $\Delta S_{\text {mix }}^{b c c}$. $\Delta H_{\text {mix }}^{b c c}$ reaches its maximum of $+7.3 \mathrm{~kJ} / \mathrm{mol}$ at 62.3 at. $\% \mathrm{Cr}$ while $\Delta H_{\text {mix }}^{C 15}$ reaches its minimum of $-8.9 \mathrm{~kJ} / \mathrm{mol}$ at 42.3 at. $\% \mathrm{Cr}$.
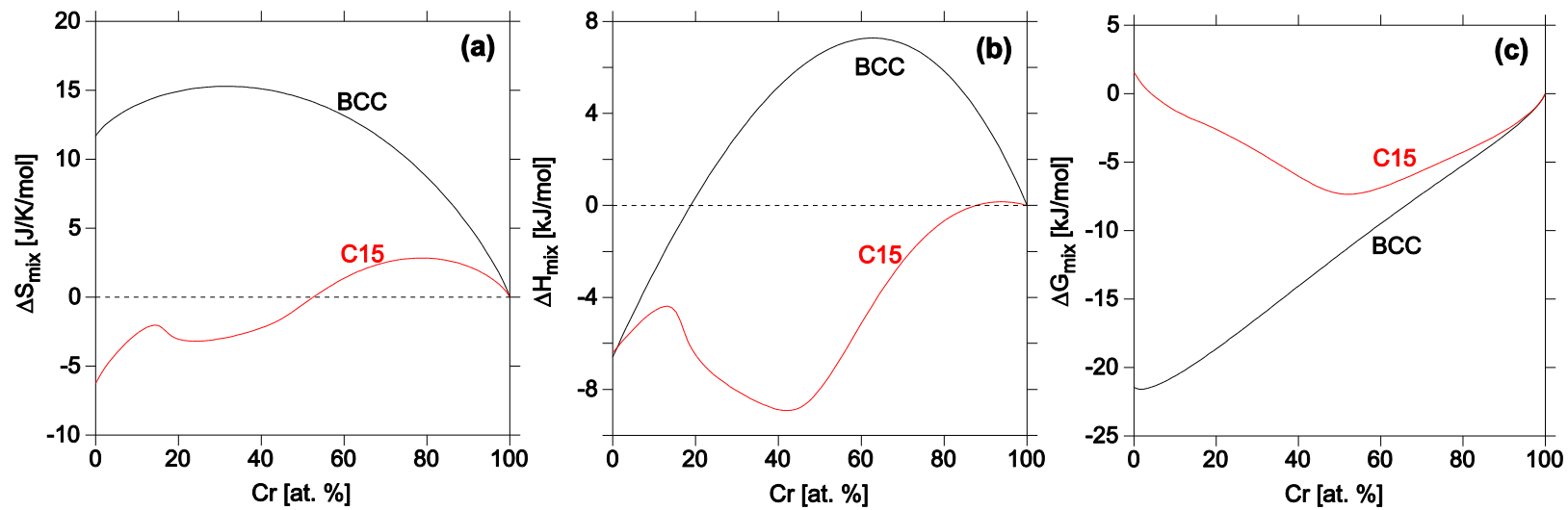

Fig. 10: calculated (a) entropy of mixing, (b) enthalpy of mixing and (c) Gibbs energy of mixing of the $\mathrm{BCC}$ and $\mathrm{C} 15$ Laves phases in $\mathrm{Cr}_{\mathrm{x}} \mathrm{MoNbTaVW}$ at $1000{ }^{\circ} \mathrm{C}$ as a function of $\mathrm{Cr}$ contents. The reference states for all components are the $\mathrm{BCC}$ phase at $1000{ }^{\circ} \mathrm{C}$ and $1 \mathrm{~atm}$.

The chemical dependence of the thermodynamic mixing properties of the BCC phase is shown in Fig. 11 for six pseudo-binaries at $1000{ }^{\circ} \mathrm{C}$. It can be seen that variation of $\mathrm{Cr}$ has greater impact to the thermodynamic properties than any other elements in the Cr-Mo-Nb-Ta- $\mathrm{V}$ W senary alloy system. For $\Delta S_{\text {mix }}^{b c c}, \mathrm{CrMoNb}_{\mathrm{x}} \mathrm{TaVW}$ behaves the closest to the ideal mixing followed by $\mathrm{CrMo}_{\mathrm{x}} \mathrm{NbTaVW}$ while $\mathrm{Cr}_{\mathrm{x}} \mathrm{MoNbTaVW}$ deviates from it the most. In terms of $\Delta H_{\text {mix }}^{b c c}$, increasing $\mathrm{Cr}$ contents in $\mathrm{Cr}_{\mathrm{x}} \mathrm{MoNbTaVW}$ increases it as reflected in a steep concave shape while for the rest systems it shows a shallow convex trend. The Cr-absent alloy (namely MoNbTaVW) has the lowest and dominating $\Delta H_{m i x}^{b c c}$ and thus the lowest $\Delta G_{m i x}^{b c c}$. As a result, it is expected that addition of $\mathrm{Cr}$ to MoNbTaVW will result in narrower phase field in composition and temperature for the BCC phase, despite the senary CrMoNbTaVW has higher configurational entropy than the quinary MoNbTaVW, agreeing with a prior study [21]. 

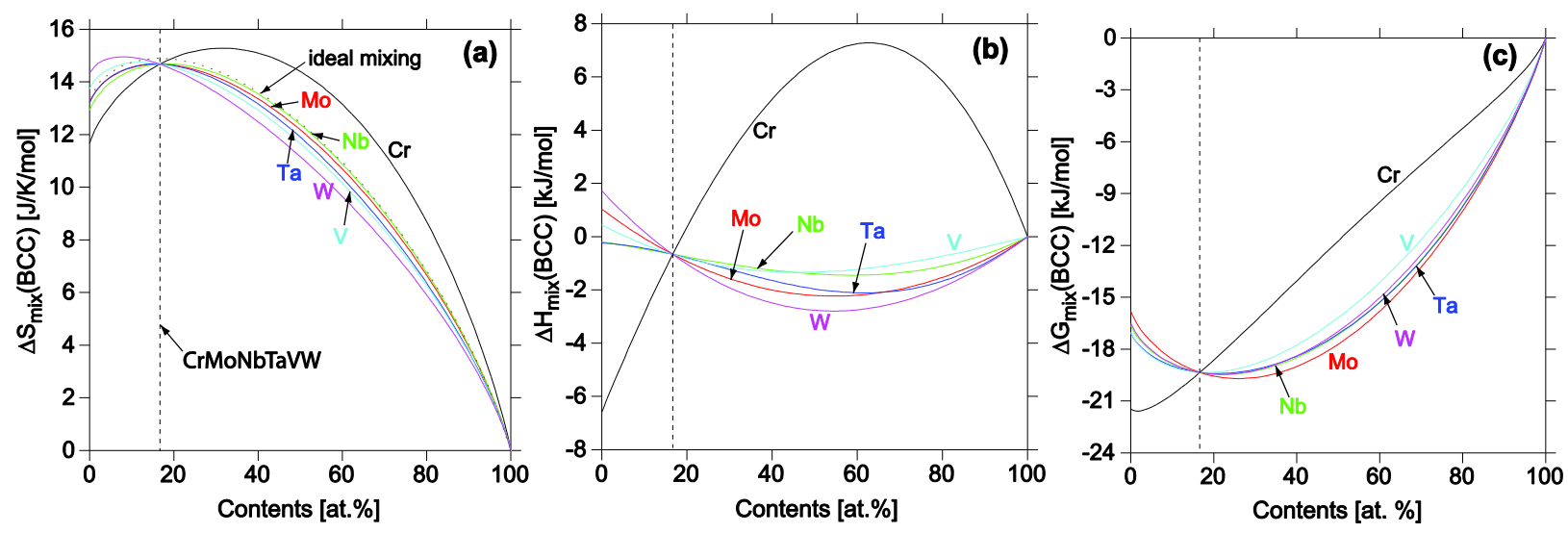

Fig. 11: calculated (a) entropy of mixing, (b) enthalpy of mixing and (c) Gibbs energy of mixing of the $\mathrm{BCC}$ phase at $1000{ }^{\circ} \mathrm{C}$ in $\mathrm{Cr}_{\mathrm{x}} \mathrm{MoNbTaVW}, \mathrm{CrMo}_{\mathrm{x}} \mathrm{NbTaVW} \mathrm{CrMoNb}_{\mathrm{x}} \mathrm{TaVW}$, $\mathrm{CrMoNbTa}_{\mathrm{x}} \mathrm{VW}, \mathrm{CrMoNbTaV}_{\mathrm{x}} \mathrm{W}$, and $\mathrm{CrMoNbTaVW}_{\mathrm{x}}$, which is labeled as Cr, Mo, Nb, Ta, V and $\mathrm{W}$ respectively in the plots. The reference states for all components are the BCC phase at $1000{ }^{\circ} \mathrm{C}$ and $1 \mathrm{~atm}$.

\section{Conclusions}

To demonstrate the design envelope of BCC phase HEAs, a senary refractory high-entropy alloy system, $\mathrm{Cr}_{\mathrm{x}} \mathrm{MoNbTaVW}(\mathrm{x}=0.5,1.0,2.0)$, was examined using CALPHAD simulations and validated experimentally using XRD and SEM. The lattice constant, density, and Vickers' micro-hardness of this HEA alloy in the as-cast state were also measured accordingly.

For three $\mathrm{Cr}$ contents $(\mathrm{x}=0.5,1.0,2.0)$ in the $\mathrm{Cr}_{\mathrm{x}} \mathrm{MoNbTaVW}$ system, all the EDS results show that the dendrite was enriched most in $\mathrm{W}$ and weakly by Mo and Ta while the interdendritic region was enriched most by $\mathrm{Cr}$ and $\mathrm{V}$ and weakly by $\mathrm{Nb}$. With the increase of the $\mathrm{Cr}$ content, the microstructure is gradually changed from the cellular to dendritic structure. In addition, the lattice constant decreases and the Vickers' hardness increases with the $\mathrm{Cr}$ content grows. CALPHAD modeling predicts phase decomposition of the BCC phase for all three alloys studied at lower temperatures, and the tendency of phase decomposition increases with the increase of $\mathrm{Cr}$ contents. This has been confirmed by the experimental testing results, where a secondary BCC phase became detectable by XRD for $\mathrm{Cr}_{2.0} \mathrm{MoNbTaVW}$.

The thermodynamic analysis on the elemental dependence of the mixing thermodynamic properties (entropy, enthalpy and Gibbs energy) in BCC phase in this senary system shows that $\mathrm{Cr}_{\mathrm{x}} \mathrm{MoNbTaVW}$ deviates from the ideal mixing the most compared to $\mathrm{CrMo}_{\mathrm{x}} \mathrm{NbTaVW}$, $\mathrm{CrMoNb}_{\mathrm{x}} \mathrm{TaVW}, \mathrm{CrMoNbTa}_{\mathrm{x}} \mathrm{VW}, \mathrm{CrMoNbTaV}_{\mathrm{x}} \mathrm{W}$ and $\mathrm{CrMoNbTaVW}_{\mathrm{x}}$. Increasing $\mathrm{Cr}$ contents sharply increases the enthalpy of mixing and accordingly the Gibbs energy of mixing of the BCC phase, and as a result, destabilizes the BCC phase significantly. The calculated entropy of mixing and enthalpy of mixing for CrMoNbTaVW are $14.7 \mathrm{~J} / \mathrm{K} / \mathrm{mol}$ and $-662.5 \mathrm{~J} / \mathrm{mol}$ respectively. The CALPHAD calculation is a valuable tool for predicting phase stability in the $\mathrm{Cr}_{\mathrm{x}} \mathrm{MoNbTaVW}$ system and provided instructive insights to the three studied HEAs. However, due to the general lacking of coverage for ternary and higher-order systems in the database TCNi7, experimental work should be performed to validate CALPHAD predictions on other HEA systems. 


\section{Disclaimer}

This project was partially funded by the Department of Energy, National Energy Technology Laboratory, an agency of the United States Government, through a support contract with AECOM. Neither the United States Government nor any agency thereof, nor any of their employees, nor AECOM, nor any of their employees, makes any warranty, expressed or implied, or assumes any legal liability or responsibility for the accuracy, completeness, or usefulness of any information, apparatus, product, or process disclosed, or represents that its use would not infringe privately owned rights. Reference herein to any specific commercial product, process, or service by trade name, trademark, manufacturer, or otherwise, does not necessarily constitute or imply its endorsement, recommendation, or favoring by the United States Government or any agency thereof. The views and opinions of authors expressed herein do not necessarily state or reflect those of the United States Government or any agency thereof.

\section{Acknowledgments}

This publication is based upon work supported by the NSF EPSCoR CIMM project under award \#OIA-1541079, and the US Department of Energy National Energy Technology Laboratory (NETL) under Award Numbers DE-FE0004734, DE-FE0011550, DE-FE0008382, DE-FE0007220, Louisiana State University Economic Development Assistantship, and the Cross-Cutting Technologies Program of NETL under the RES contract DE-FE-0004000.

\section{References}

[1] W.D. Klopp, A review of chromium, molybdenum, and tungsten alloys, Journal of the Less Common Metals, 42 (1975) 261-278.

[2] J.W. Yeh, S.K. Chen, S.J. Lin, J.Y. Gan, T.S. Chin, T.T. Shun, C.H. Tsau, S.Y. Chang, Nanostructured High-Entropy Alloys with Multiple Principal Elements: Novel Alloy Design Concepts and Outcomes, Adv. Eng. Mat., 6 (2004) 299-303.

[3] P.K. Huang, J.W. Yeh, T.T. Shun, S.K. Chen, Multi - Principal - Element Alloys with Improved Oxidation and Wear Resistance for Thermal Spray Coating, Advanced Engineering Materials, 6 (2004) 74-78.

[4] C.-Y. Hsu, J.-W. Yeh, S.-K. Chen, T.-T. Shun, Wear resistance and high-temperature compression strength of Fcc $\mathrm{CuCoNiCrAl0}$. 5Fe alloy with boron addition, Metallurgical and Materials Transactions A, 35 (2004) 1465-1469.

[5] Y.J. Zhou, Y. Zhang, Y.L. Wang, G.L. Chen, Solid solution alloys of AlCoCrFeNiTi x with excellent room-temperature mechanical properties, Applied physics letters, 90 (2007) 181904181904.

[6] O.N. Senkov, G.B. Wilks, D.B. Miracle, C.P. Chuang, P.K. Liaw, Refractory high-entropy alloys, Intermetallics, 18 (2010) 1758-1765.

[7] O.N. Senkov, J.M. Scott, S.V. Senkova, F. Meisenkothen, D.B. Miracle, C.F. Woodward, Microstructure and elevated temperature properties of a refractory TaNbHfZrTi alloy, Journal of Materials Science, 47 (2012) 4062-4074.

[8] O.N. Senkov, J.M. Scott, S.V. Senkova, D.B. Miracle, C.F. Woodward, Microstructure and room temperature properties of a high-entropy TaNbHfZrTi alloy, Journal of Alloys and Compounds, 509 (2011) 6043-6048.

[9] B. Zhang, M. Gao, Y. Zhang, S. Yang, S. Guo, Senary refractory high entropy alloy MoNbTaTiVW, Materials Science and Technology, 31 (2015) 1207-1213. 
[10] M.C. Gao, B. Zhang, S. Yang, S.M. Guo, Senary Refractory High-Entropy Alloy HfNbTaTiVZr, Metallurgical and Materials Transactions A, (2015) 1-13.

[11] C.-C. Juan, M.-H. Tsai, C.-W. Tsai, C.-M. Lin, W.-R. Wang, C.-C. Yang, S.-K. Chen, S.-J. Lin, J.-W. Yeh, Enhanced mechanical properties of HfMoTaTiZr and HfMoNbTaTiZr refractory high-entropy alloys, Intermetallics, 62 (2015) 76-83.

[12] M.C. Gao, D.E. Alman, Searching for Next Single-Phase High-Entropy Alloy Compositions, Entropy, 15 (2013) 4504-4519.

[13] M.C. Gao, Ö.N. Doğan, P. King, A.D. Rollett, M. Widom, The first-principles design of ductile refractory alloys, JOM, 60 (2008) 61-65.

[14] B. Zhang, M. C. Gao, Y. Zhang, S.M. Guo, Supporting Data for Senary Refractory HighEntropy Alloy CrxMoNbTaVW, Data in Brief, submitted.

[15] E. Scheil, Z. Metallkd, 34 (1942) 70-72.

[16] G.H. Gulliver, The quantitative effect of rapid cooling upon the constitution of binary alloys, Journal of the Institute of Metals, 9 (1913) 120-157.

[17] W. Benenson, H. Stöcker, Handbook of physics, Springer Science \& Business Media2002. [18] W.C. Winegard, An introduction to the solidification of metals, Institute of Metals 1964.

[19] A. Leo, C. Hansch, D. Elkins, Partition coefficients and their uses, Chemical reviews, 71 (1971) 525-616.

[20] W.B. Pearson, Crystal chemistry and physics of metals and alloys, (1972).

[21] C. Zhang, M.C. Gao, Chapter 12: CALPHAD Modeling of High-Entropy Alloys, in: M.C.

Gao, J.W. Yeh, P.K. Liaw, Y. Zhang (Eds.) High-Entropy Alloys: Fundamentals and Applications, Springer, Cham, 2015.

[22] M. Widom, Chapter 8: Prediction of structure and phase transformations, in: M.C. Gao, J.W. Yeh, P.K. Liaw, Y. Zhang (Eds.) High-Entropy Alloys: Fundamentals and Applications, Springer, Cham, 2015. 